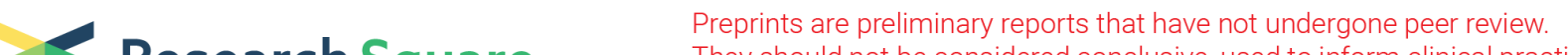 Research Square They should not be considered conclusive, used to inform clinical practice, or referenced by the media as validated information.
}

\section{Influence of the Welding Angle on the Mechanical Behavior of Plates obtained by the Tailor Welded Blank (TWB) Process}

Wellington Augusto dos Santos ( $\nabla$ wellington.santos1@stellantis.com )

Pontifical Catholic University of Minas Gerais: Pontificia Universidade Catolica de Minas Gerais

Etiene Pereira de Andrade

Universidade Federal de Minas Gerais

Guilherme Souza Assunção

Universidade Federal de Minas Gerais

Izabela Ângela Santos

Departamento de Engenharia Mecânica Pontifícia Universidade Católica de Minas Gerais, Instituto

Politécnico da PUC Minas

Gilmar Cordeiro da Silva

Departamento de Engenharia Mecânica Pontifícia Universidade Católica de Minas Gerais, Instituto Politécnico da PUC Minas

\section{Research Article}

Keywords: Tailor Welded Blank (TWB), Optimal forming angle, tensile test, Influence of Thickness

Posted Date: May 7th, 2021

DOI: https://doi.org/10.21203/rs.3.rs-489777/v1

License: (9) (1) This work is licensed under a Creative Commons Attribution 4.0 International License. Read Full License 


\section{Abstract}

Tailor Welded Blank (TWB) is a top-welding technique (by unconventional processes) of sheets of different specifications (materials, thicknesses and/or coatings). Because it allows localised distribution of mechanical properties and mass, it can optimise the relationship between structural rigidity and total weight. The great challenge of this technique is to combine two processes with completely different demands, welding and mechanical forming. This work investigates the mechanical behavior of sheets obtained by the Tailor-blank process from the determination of the optimum angle. We performed tensile tests on sheets with different weld line inclinations, as the general objective is to consolidate knowledge about the process, characterise the conditions for sheet formation obtained by the technique, in a safe conformation range, with complex contours, dimensional qualities and free of catastrophic failure. Steel sheets, interstitial free (IF), of $1.10 \mathrm{~mm}$ and $0.65 \mathrm{~mm}$ thick were used. The TWB was applied with a welding line oriented from $0^{\circ}$ to $90^{\circ}$ (ranging from $15^{\circ}$ to $15^{\circ}$ ). The optimum angle obtained was $30^{\circ}$, where there was a good relationship between the breaking load, purely tensile and shear stresses, and the total elongation. In relation to the angle of $0^{\circ}$, the optimum angle presented a superior elongation of approximately $40 \%$. It was still possible to notice that the thickness of the plates influenced the optimum angle, even if the LSR (Limit Strength Ratio) is close.

\section{Introduction}

Investment in manufacturing methods, and the development of new materials and technologies led to into new products that have better final characteristics in relation to weight, safety and structural performance. According to [1], the body represents about $25-30 \%$ of the total weight of a midsize vehicle. Therefore, the reduction of the vehicle's weight is of great importance, because it can reduce fuel consumption and thus the emission of polluting gases, which suits the needs of the 21 st century.

There are many ways to reduce weight in a vehicle, one of which is the Tailor Welded Blank (TWB) technique.TWB consists of the union of two or more metal sheets through the welding process, which makes it possible to join sheets of different materials, thicknesses, mechanic properties and coatings. This technique aims to address the need for greater mechanical resistance in specific locations and to reduce cost, which allows the final part to present the necessary characteristics for impact regions or complex geometries [2-5].

The great challenge in the process of stamping TWBs is the reduced conformability of the blanks. Material of less thickness can present a preferential deformation and break prematurely. In addition to the mechanical effects, microstructural issues can arise due to the fused zone (FZ), which can negatively influence the shape of the TWBs, through the development of martensitic structures.

Transformations due to the heat affected-zone (HAZ) can generate from local softening to complex phase transformations in conditions out of balance [6-7]. The main failure modes during the formation of TWBS are a break of the thinner material and a break in the weld due to FZ and HAZ, which are related 
to the orientation of the weld line in relation to the direction of application of the main effort and the quality of the blank material [8-9].

Zadpooor et al. [10] performed a review of the TWB method. The authors reported that the flow and the tensile strength are linked to the orientation of the weld line, where welds that are carried out longitudinally present better results than transversal welds. The authors also reported that the ductility of the welded material is influenced (in addition to the orientation of the weld) by the thickness ratio of the welded materials.

Riahi et al. [11] in their research showed the influence of the positioning of the weld line on the formability of TWBs. Their main conclusion was that by reducing the thickness ratio of the TWB blanks, their formability was increased. It was also noticed that when moving the weld line towards the thicker sheet, the formability was also increased.

$\mathrm{Li}$ and Lin [12] aimed to expand the knowledge about the conformability of TWBs. The authors presented curves of tensile tests, where it is possible to observe that the base materials suffer a reduction in the deformation just for being welded. This result is influenced by ZTA.Their study also addresses the Erichsen test to assess the TWB deformability, through experiments and numerical simulation. The authors concluded at the end of the article, that the tensile test shows that the plastic deformation is concentrated in the base material when the weld varies from $30^{\circ}$ to $90^{\circ}$, and the stress concentration is in the weld when the weld is at $90^{\circ}$.

According to Nalli et al. [13], Safdarian [14] and Ahmetoglu et al. [15] on the two welded materials there is a balance of forces at work, where $\mathrm{Fa}=\mathrm{Fb}$. Therefore, disregarding the metallurgical effects, the threshold can be obtained by Eq. 1:

$$
\operatorname{LSR}=\left(\frac{\sigma_{\mathrm{YB}}}{\sigma_{\mathrm{TA}}}\right)=\left(\frac{\mathrm{t}_{\mathrm{OA}}}{\mathrm{t}_{\mathrm{OB}}}\right)
$$

Where: LSR = Limit Strength Ratio, = Yield Strength for material $B,=$ Tensile Strength for material $A,=$ Initial thickness of material $A e=$ Initial thickness of material $B$. The threshold represented by the LSR depends on the proportion of thickness of the two materials and if it is not respected, the final product may develop serious quality problems [16]. This is an important factor because it can help to prevent the failure mode because the fracture approaches the weld as the thickness ratio increases. When the welding line is homogeneous and the thickness ratio is close to the unit, the failure occurs in the sheet with less mechanical resistance (less thick) and far from the welding line [17].

Taking into account the cited research, Andrade et al. [16] evaluated the formability of the TWB according to the variation of the wed 1000 relative angulations. Angles from 0 to $70^{\circ}$ were evaluated, with a variation of $5^{\circ}$ in the Rolling Direction (RD). According to the research results, the ideal or adequate working angle is around $25^{\circ}$, which allows a good relationship between shear and rupture load. To achieve good TWB formability, it is necessary to incline the weld at $25^{\circ}$ in relation to the lamination direction of the sheet towards the material of greater thickness or mechanical resistance. 
TWB is a promising technique and studies aimed at optimizing its application are essential for an effective result, and can enable its use, which is important not only for cost reduction, but also for environmental issues. This study uses the research by Zadppor et al. [10], which states that the LE and LRT values of longitudinally welded specimens can be up to $12 \%$ better than the transversal ones, and the results by Andrade et al. [16]. In particular, this study aims to analyse the influence of the welding angle on the mechanical behavior of sheets obtained by the TWB process, through tensile testing and analysis in the SEM, to consolidate an optimal angle. Different thicknesses from the studies by [16] were used. This factor was done with the objective of evaluating the influence of the thickness variable in the optimal angle.

\section{Materials And Methods}

Table 1 shows the parameters for welding.

\section{Table 1}

Parameters for welding

\begin{tabular}{|lllll|}
\hline Equipment & $\begin{array}{l}\text { Rated } \\
\text { Power }\end{array}$ & $\begin{array}{l}\text { Average } \\
\text { Power }\end{array}$ & Shielding gas & $\begin{array}{l}\text { Welding } \\
\text { speed }\end{array}$ \\
\hline $\begin{array}{l}\text { Laser of } \\
\mathrm{CO}_{2} \text { SoundRonic } B\end{array}$ & $8.0 \mathrm{~kW}$ & $65 \%$ & $\begin{array}{l}\text { He pure, with flow rate of } \\
10 \mathrm{~L} / \mathrm{min}\end{array}$ & $6.5 \mathrm{~m} / \mathrm{min}$ \\
\hline
\end{tabular}

Uniaxial traction tests (to determine mechanical properties) and microstructural analysis were performed with the assistance of an optical microscope. Triplicate sampling was used for greater reliability of the results.

\subsection{Materials}

Table 2 shows the chemical composition of the steels that we used to make TWB sheets and in Table 3 we give their mechanical properties.

\section{Table 2}

Chemical composition of IF steels used in TWB

\begin{tabular}{|lllllllll|}
\hline Element (\%) & $\mathbf{C}$ & $\mathbf{M n}$ & $\mathbf{P}$ & $\mathbf{S}$ & $\mathbf{S i}$ & $\mathbf{N}$ & $\mathbf{N b}$ & $\mathrm{Ti}$ \\
\hline IF FEP 05 & 0.0018 & 0.1350 & 0.0120 & 0.0100 & 0.0050 & 0.00420 & 0.0030 & 0.0570 \\
\hline IF FEE 210 & 0.0021 & 0.4320 & 0.0360 & 0.0120 & 0.0050 & 0.00360 & 0.0024 & 0.0260 \\
\hline
\end{tabular}

\section{Table 3}




\begin{tabular}{|l|lllll|}
\hline Material & Thickness [mm] & LE [MPa] & LRT [MPa] & LSR \\
\hline IF CSN FEE 210 & 1.10 & 217 & 346 & \multirow{2}{*}{1.692} \\
\cline { 1 - 4 } IF CSN FEP05 & 0.65 & 157 & 284 & \\
\hline
\end{tabular}

\subsection{Uniaxial Traction Tests}

The tensile tests were performed according to the ISO 6892-1 [18] standard, with specimens whose dimensions are shown schematically in Fig. 1.

To remove the specimens, different plates were selected randomly from the inside panel of a vehicle door that was manufactured using the TWB technique. The blank adopted for extracting the CPs is shown in Fig. 2.

The blank shown in Fig. 2 was cut into plates smaller than $300 \mathrm{~mm} \times 300 \mathrm{~mm}$ according to Andrade's work [19]. Different guidelines for the welding line were adopted, as shown in Fig. 3.

The angle $a$ of the relative inclination of the weld line varied between $0^{\circ}$ and $90^{\circ}$ (with increases of $15^{\circ}$ in $15^{\circ}$ ). The bodies used in the tensile test are shown in Fig. 4 .

White markings made on the $\mathrm{CP}$ were used as a basis for alignment on the machine's traction claws. We worked with an Instron ${ }^{\circledR} 3382$, equipped with a 2663 - 821 video extensometer and BlueHill®2 data acquisition software, with an upper head movement speed of $1.2 \mathrm{~mm} / \mathrm{s}$. The tests were interrupted automatically as soon as the rupture of the specimens was verified.

Data regarding the breaking load and maximum elongation of each specimen were collected. The rupture load was decomposed into purely tensile load and shear load, according to Hollomon's equation and Ludwik's law.

\subsection{Scanning Electron Microscopy (SEM)}

To perform the electron beam scanning electron microscopy (SEM), the QUANTA® scanning electron microscope, model FEG 250, was used. The beam used was $20 \mathrm{kV}$ with a magnitude ranging from $200 \mathrm{X}$ to 5000X. For comparison purposes, the microscopy of the weld itself and samples with relative inclinations of the welding line of $30^{\circ}$ and $90^{\circ}$ were evaluated.

\section{Results And Discussions}

\subsection{Tensile Tests}

As shown in Fig. 4, in addition to tests ranging from $15^{\circ}$ to $15^{\circ}$, three different specimens were also prepared. The objective was to try to reproduce, in the uniaxial traction, failures that could occur during 
the forming of the plates in the region of bi-linearity of the weld line. The (qualitative) results are shown in Fig. 5.

Regardless of the position of the weld line, the fracture always occurs in the thinner sheet (and less mechanical resistant). However, as previously pointed out by [20], the exact location of the fracture is random. In the case of " $\mathrm{V}$ " weld, it is noticed (albeit subtly) that there is an enlargement of the specimen in the weld region. This can be explained by the small contribution of the base material FEP 05 and the greater resistance of the weld to break.

For the tensile tests, it was chosen to represent the results in terms of load and not tension. This is because the works used as reference do not make the methodology that they used to convert the load data into traction (not showing whether the cross-sectional area used was that of the smaller or thicker plate) and the fact that the maximum load supported by the material is critical data in stamping.

A graph corresponding to the relationship between the breaking load and the relative inclination angle of the weld line is shown in Fig. 6.

The behavior presented by the rupture load profile is consistent with that found by [19], which reaffirms his theory that the maximum resistance of a TWB does not depend on the weld (as long as it is previously qualified), and is more related to the materials that make up the plates that give rise to the blank. This goes against what is advocated by $[14,21,22]$.

It stands out that there is a relative discrepancy for the $90^{\circ}$ angle. This happens because in this condition the weld line passes through the entire specimen. Thus, according to [23-24], the weld would have a considerable effect on the mechanical properties obtained through the tensile test. This can be proven on the starting point of the rupture of this specimen, as shown in Fig. 7.

There is an alternative method that, when conciliated with the microhardness profile pointed out by [25, $19,26]$, can be valid in the survey of the mechanical properties of FZ and HAZ. The need to validate the proposed methodologies is therefore reinforced to more precisely characterise the deformations in the TWB welded joint.

The finding that the breaking load of a TWB is almost independent of the weld itself, associated with the base of the dependence relationship between the angle of the cutting plane and the stresses, presented by $[6,27]$, reinforces the need to evaluate the optimal angle. This allows a better relationship between the breaking load, the purely tensile load and the shear, and combined with a better elongation.

A graph corresponding to the relationship between the purely tensile load and the relative angle of the weld line is shown in Fig. 8.

The tendency is for the purely traction load, on the base materials, to reach nullity. This can be confirmed as suggested by the work of [12], which argues that a more effective characterisation of the weld can (by means of tensile tests with standard sized specimens) occur with the weld making up the entire sample. 
In addition, as pointed out by [27], the purely traction load is determinant for fragile type fractures, which does not occur in the researched samples. Hence, once again, failure does not depend effectively on the tensile load but on the combination of the shear, total load and relative angle of inclination of the weld.

The purely tensile load is portrayed in the work of [28] as being important for determining the behavior of the weld through the Mixture Rule. In the studies of [19] it was found that only geometric factors are taken into account and that the presence of HAZ (different for each of the basic materials) can invalidate the results, which in fact occurred.

It was also decided to analyse the total shear load on the specimens. A graph corresponding to the relationship between the purely shear load and the relative slope angle of the weld line is shown in Fig. 9.

For the $90^{\circ}$ angle, the shear stress, as well as the purely tensile stress, tends to be zero on the base materials. This indicates indicating that the stress acts primarily on the weld line. The nullity of this tension for an angle of $0^{\circ}$ indicates that only tension stresses act on the weld line and the base materials, which confirms what was pointed out by $[27,6]$.

As indicated by [19], there is a behavior that is somewhat interesting: the shear stress is the same for complementary angles (such as $15^{\circ}$ and $75^{\circ}$, for example). It is noteworthy that this does not depend only on Eq. (2), which takes into account the product sine and cosine (which is similar for complementary angles), but also the rupture load. Because this property is mainly associated with the base materials and the weld proved to be qualified, the similarity behavior of the shear stress was proven.

Our intention, when developing this research with a greater number of conditions and bodies of evidence was to prove what was found by [19] in his Master's dissertation. Because the pattern mentioned was not found in any researched article, not even in the works of [11,12], which used different guidelines for the welding line. It turns out that it did not focus on the analysis of shear stress, only on the deformation.

$[11,14,28,25]$ found only that the total load on the specimens did not depend significantly on the orientation of the weld line. This theory was proven in this work. Other research, such as that of [14], worked with the displacement relative to the center of the specimen of the weld line but always keeping it perpendicular to the direction of the lamination of the plates. Perceptible differences were found only in the so-called limit dome height test (LDH), focusing mainly on total dome deformation.

Deformation analysis was performed using data from the total elongation of the specimens. A graph corresponding to the relationship between the total elongation and the relative angle of the weld line is shown in Fig. 10.

When working with conformation, it is necessary to analyse the material's ability to deform. To do this, it works, in general, as the so-called exponent of hardening [27, 29]. The purpose of verifying the total elongation of the specimens was to analyse, albeit indirectly, what is the ideal orientation condition of the weld line that would allow greater deformation. According to the data presented, there is a tendency for the maximum deformation supported by the samples to increase as the relative orientation angle of the 
weld line increases up to the $30^{\circ}$ angle, $34 \%$ elongation, right after a drop and for the angles of $45^{\circ}, 60^{\circ}$ and $75^{\circ}$ and keeps the elongation between 21 and $23 \%$, lower values, but very close to the elongation found for the angle $0^{\circ}, 24 \%$, and for the angle of $90^{\circ}$ it reaches the maximum value of $43 \%$.

This observation proves, once again, what was found by [19], and it indicates that there is an optimal working angle that provides a good relationship between the breaking load, the purely tensile and shearing stresses and the total elongation. In the case that we analysed, this angle is close to $30^{\circ}$.

\subsubsection{Scanning Electron Microscopy (SEM)}

Figure 11 shows the micrographs, obtained by SEM, with different magnifications, for the weld itself.

According to [30], porosities are allowed as long as their maximum diameter does not exceed $30 \%$ of the smallest thickness of the plates that make up the TWB (the smallest thickness is $0.65 \mathrm{~mm}$, for this study). Some discontinuities, such as bites, that are allowed as long as the angle of the bite with the piece does not exceed $90^{\circ}$. In the SEM images, it is verified that the fracture occurred in a ductile way, due to the nucleation and growth of the dimples [31,32]. Discontinuities that disqualify the weld are not noticeable or evident. As pointed out by the works of [16], these mechanical tensile tests offer good representativeness because the weld is qualified.

Figure 12 shows the micrographs that we obtained by SEM, with different magnifications, for welding with a relative inclination of $30^{\circ}$.

In the SEM images, it can be seen that the fracture also occurred in a ductile form, due to the nucleation and growth of the dimples) [31,32]. The dimples are apparently smaller and more homogeneous than in the weld itself, which shows a greater contribution of the base materials. In this case, because the fracture occurred in the thinner sheet, good ductility and homogeneity of the IF FEE 210 steel is therefore indicated. There also appears to be a fracture onset, which is typical of tensile specimens [27].

Figure 13 shows the micrographs, obtained by SEM, with different magnifications, for welding with a relative inclination of $90^{\circ}$.

This is the micrograph that is most similar to that of the weld itself, given that the rupture of the specimen occurred in $\mathrm{V}$, with the fracture starting at the weld. As pointed out in the tensile tests, when the weld line has a relative orientation of $90^{\circ}$, the specimen ceases to have intermediate mechanical behavior between the base metals and starts to behave like the weld itself. In this situation, it is the region of most demand and effective traction.

The fracture occurred in a ductile form (due to the nucleation and growth of the dimples [31, 32]. However, there is a greater irregularity of the dimples and a more continuous fracture, showing rapid growth, coalescence and propagation of the dimples. 


\section{Conclusion}

Through the results of the work, it was possible to expand the knowledge of the TWB technique, thus increasing the probability of its application with greater efficiency and effectiveness. The following conclusions can be highlighted:

1. The purely traction load reaches a maximum at an angle of $0^{\circ}$ and it decays according to the increase in angulations, reaching zero at an angle of $90^{\circ}$.

2. The maximum shear loads are found for the $45^{\circ}$ angle and the load values were very close for the complementary angles.

3. There is an increase in the elongation between the angles from 0 to $30^{\circ}$, and right after there is a decay and a maximum elongation in the angle of $90^{\circ}$.

4. According to the optical microscopy, it is possible to see that at the angle of $30^{\circ}$ the rupture occurs in the material of less thickness, in the angle of $90^{\circ}$ there is a rupture in the weld and both fractures occur in ductile forms, where there is coalescence of dimples.

5. According to the results, the optimal angle is $30^{\circ}$, which provides a good relationship between the breaking load, the purely tensile and shearing stresses and the total elongation.

6. It is possible to conclude that the individual thicknesses also influence this angle because a small variation of 0.022 in LSR, generated a variation of $5^{\circ}$ in the optimal angle.

\section{Declarations}

\section{Compliance with Ethical Standards}

The present study did not have sources of government funding, nor needed experiences in humans or animals.

The authors are in accordance with JAMT policy and therefore, according to the analyzes carried out, conflicts of interest.

It is stated that:

- The present manuscript was not subjected to other newspapers and magazines

- The article is original, based on a master's dissertation survey

- It is a complete study, without partitioned submissions, whether in JAMT or other journals

- There is no type of plagiarism or explicit print

\section{Consent to Participate}

There was no research with humans or animals. Therefore, no consent of participation was required in this regard. 


\section{Consent to Publish}

There was no research with humans or animals. The data and results obtained from surveys with metal samples have taken place together with the authors. There is consensus for your publication and dissemination.

\section{Authors Contributions}

1) There are few publications in relation to the analysis of the influence of the soldering line and its relative inclination in the conformability and the mechanical strength of a Welded Blank Tailor (TWB). This article will contribute as a methodology of analysis and validation of this phenomenon, being relevant for academic purposes and, above all, industrial

2) The great novelty is a methodological process, based on the theory of fracture conformation and mechanics, which aims to qualify TWBs and to obtain, for different materials, which relative slope of the most suitable weld line for conformity improvement and mechanical properties

(3) The article has industrial applications both in the area of welding and in conformation, the industry being the most beneficiary of automotive and advanced welding and conformation processes.

\section{Funding}

The present research did not receive funds from research bodies or philanthropic institutions. The costs of the study were benched by the authors themselves, with some of the materials and bodies of proof assigned by Fiat Chrysler Automobiles Brazil LTDA.

\section{Competing Interests}

The authors have no relevant financial or non-financial interests to disclose.

The authors have no conflicts of interest to declare that are relevant to the content of this article.

All authors certify that they have no affiliations with or involvement in any organization or entity with any financial interest or non-financial interest in the subject matter or materials discussed in this manuscript.

The authors have no financial or proprietary interests in any material discussed in this article.

The authors are given the copyrights of this Article to JAMT, if necessary and if necessary. There is no conflict of interest and is not expected financing or jobs for employment or work. There is also no financial interest in the present research.

\section{Availability of data and materials}

Authors declare total availability of dukes, tables and figures present non-article, not opposing their disclosure. 


\section{References}

1. TOURRUCÔO M (1999) Estudo de Chapas de Elevada Resistência para a Indústria Automobilística. 103 f. Dissertação (Mestrado) - Curso de Engenharia Metalúrgica, Universidade Federal do Rio Grande do Sul, Porto Alegre, 2009

2. Assunção E, Quintino L, Miranda R (2009) Comparative study of laser welding in tailor blanks for the automotive industry. The International Journal of Advanced Manufacturing Technology 49:123-131

3. Li G, Xu F, Huang X, Sun G (2015) Topology optimization of an automotive tailor-welded blank door. J Mech Des 137:055001-055008

4. Santos AD, Andrade WA, Assunção EPereiraD, Silva GS, Gilmar Cordeiro da.(2020) Finite and numerical simulations applied in Tailor Welded Blank. Global Journal of Research in Engineering, 20:46-59

5. Parente M, Safdarian R, Santos AD, Loureiro A, Vilaca P, Jorge N, R. M (2015) A study on the formability of aluminum tailor welded blanks produced by friction stir welding. The International Journal Of Advanced Manufacturing Technology 83:2129-2141

6. Callister WD, Rethwisch DG (2016) Ciência e engenharia de materiais: uma introdução.LTC. GEN Grupo Editorial Nacional, São Paulo

7. Krauss G (1990) Steels: heat treatment and processing principles, 2nd edn. ASM International, Ohio, $497 p$

8. Abbasi M, Ketabchi M, Labudde T, Prahl U, Bleck W (2012) New attempt to wrinkling behavior analysis of tailor welded blanks during the deep drawing process. Materials Design 40:407-414. http://dx.doi.org/10.1016/j.matdes.2012.04.015

9. Meinders T, Van Den Berg A, Huétink J (2000) Deep drawing simulations of tailor blanks and experimental verification. J Mater Process Technol 103:65-73

10. Zadpoor AA, Sinke J, Benedictus R, Pieters R (2008) Mechanical properties and microstructure of friction stir welded tailor-made blanks. Materials Science Engineering: A 494:281-290

11. Riahi m; amini, sabbaghzadeh a, torkamani j, M.J (2012) Analysis of weld location effect and thickness ratio on formability of tailor welded blank. Science and Technology of Welding And Joining17:282-287

12. Li Y, Lin J (2015) numerical investigations of constraint effect on deformation behavior of tailorwelded blanks. J Mater Eng Perform 24:.2957-2969

13. Nalli F, Spena PR, Cortese L, Reiterer D (2017) Global-local characterization and numerical modeling of TWB laser welded joints. In: International Mechanical Engineering Congress and Exposition IMECE, 5., 2017, Flórida (Tampa). Proceedings of the ASME 2017 International Mechanical Engineering Congress and Exposition. Flórida (Tampa): 1-8

14. Safdarian R (2016) The effects of strength ratio on the forming limit diagram of tailor-welded blanks. Ironmaking Steelmaking 45:17-24 
15. Ahmetoglu MA, Brouwers D, Shulkin L, Taupin L, Kinzel GL, Altan T (1995) Deep drawing of round cups from tailor-welded blanks. Journal of Material Processing Technology 53:684-694

16. Andrade EP, Assunção GS, Santos WA, Felizardo I, Bracarense AQ (2019) Caracterização mecânica e análise microestrutural de chapas obtidas pelo processo de Tailor Welded Blank (TWB). Soldagem Inspeção 24:e2425. https://doi.org/10.1590/0104-9224/SI24.25

17. SADOUN AM, MESELHY AF, DEABS AW Improved strength and ductility of friction stir tailor-welded blanks of base metal AA2024 reinforced with interlayer strip of AA7075. Results in Physics, v. 16, p. 102911,2020

18. International Organization For Standardization (2016) 6892-1: Metallic materials -Tensile testing Part 1: Method of test at room temperature, 2 edn. ISO, Geneva, 79 p

19. Andrade EP de. Caracterização mecânica e análise microestrutural de chapas obtidas pelo processo de Tailor Welded Blank (TWB) (2019) Dissertação (Mestrado em Engenharia Mecânica) Universidade Federal de Minas Gerais, Belo Horizonte

20. Andrade EPereiraD, Santos WA, Bracarense D, Alexandre Queiroz. (2017) Caracterização mecânica e análise de falhas de chapas fabricadas pelo processo de Tailor Welded Blank submetidas a estampagem profunda. Anais do 54º Seminário de Laminação e Conformação, 54:293-301

21. Fazli A (2016) Investigation of the effects of process parameters on the welding line movement in deep drawing of tailor welded blanks. International Journal of Advanced Design Manufacturing Technology 9:45-52

22. Gautam V, Raut VM, Kumar D, Ravi (2016) Analytical prediction of spring back inbending of tailorwelded blanks incorporating effect of anisotropy and weld zone properties.Proceedings of the Institution of Mechanical Engineers, Part L: Journal of Materials, 232: 294-306

23. Merklein M, Johannes M, Lechner M, Kupert A (2014) A review on tailor blanks-Production, applications and evaluation. J Mater Process Technol 214:151-164

24. Kumar TK, Reddy KJ (2015) Tailor Welded Blanks. International Journal of Research I n Engineering Technology 4(2):63-72

25. ASSUNÇÃO GS; ANDRADE, Etiene Pereira de; SANTOS, Wellington Augusto dos; FELIZARDO, Ivanilza Felizardo; BRACARENSE, Alexandre Queiroz Bracarense. Caracterização Mecânica da Região Soldada de Tailor Welded Blanks (TWB) a Partir do Perfil de Microdureza. Soldagem \& Inspeção, [s.I.], v. 24, p.1-10, 2019. FapUNIFESP (SciELO). http://dx.doi.org/10.1590/ 0104-9224/si24.32

26. Korouyeh RS, Naeini HM, Liaghat G (2012) Forming limit diagram prediction of tailor-welded blank using experimental and numerical methods. J Mater Eng Perform 21:2053-2061

27. Cetlin PR, Helman H (2005) Fundamentos da conformação: Mecânica dos metais. Artliber, São Paulo

28. Khan A, Suresh VVNSatya, Regalla SP (2014) Effect of thickness ratio on weld line displacement in deep drawing of aluminium steel tailor welded blanks. Procedia Materials Science 6:401-408

29. Hosford WF, Caddell RM (2007) Metal forming mechanics and metallurgy, 3rd edn. Cambridge University Press, Cambridge, 312 p. http://dx.doi.org/10.1017/CBO9780511811111 
30. Kinsey BL, Wu X (2011) Tailor welded blanks for advanced manufacturing. Woodhead Publishing Limited, Cambridge, $217 \mathrm{p}$

31. Dharan CKH, Kang BS, Finnie I (2016) Cleavage and ductile fracture mechanisms the microstructural basis of fracture toughness. In: Dharan CKH, Kang BS, Finnie lain. Finnie's Notes on Fracture Mechanics: Fundamental and Practical Lessons. Springer, Nova lorque

32. Affonso, Luiz Otávio Amaral. (2007) Ductile and brittle fractures. In: AFFONSO, Luiz Otávio Amaral.Machinery Failure Analysis Handbook: Sustain Your Operations and Maximize Uptime. Houston: Gulf Publishing Company. Cap. 4. p. 33-42

\section{Figures}

420

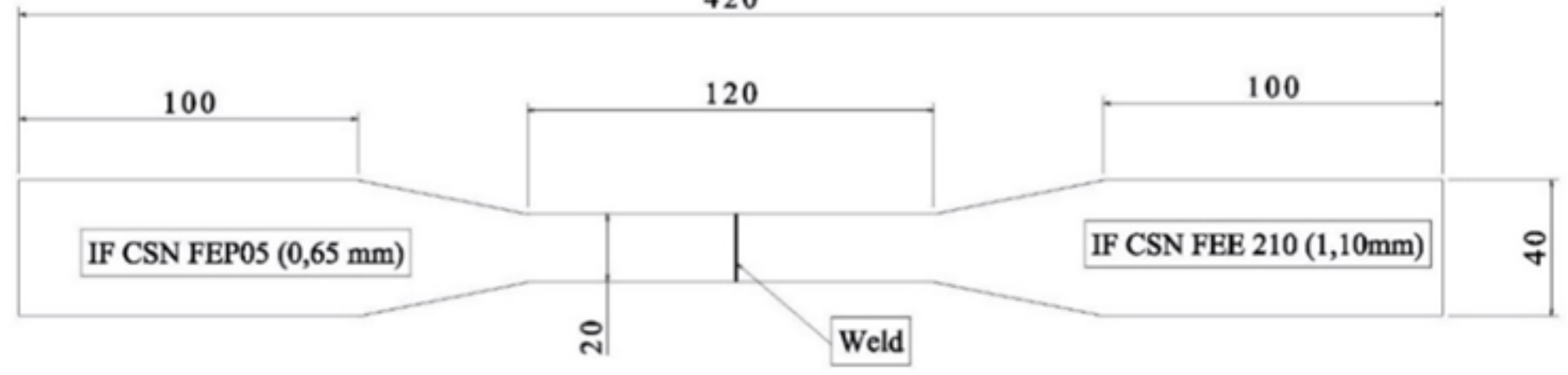

\section{Figure 1}

Schematic representation of dimensions of specimens used in uniaxial tensile tests
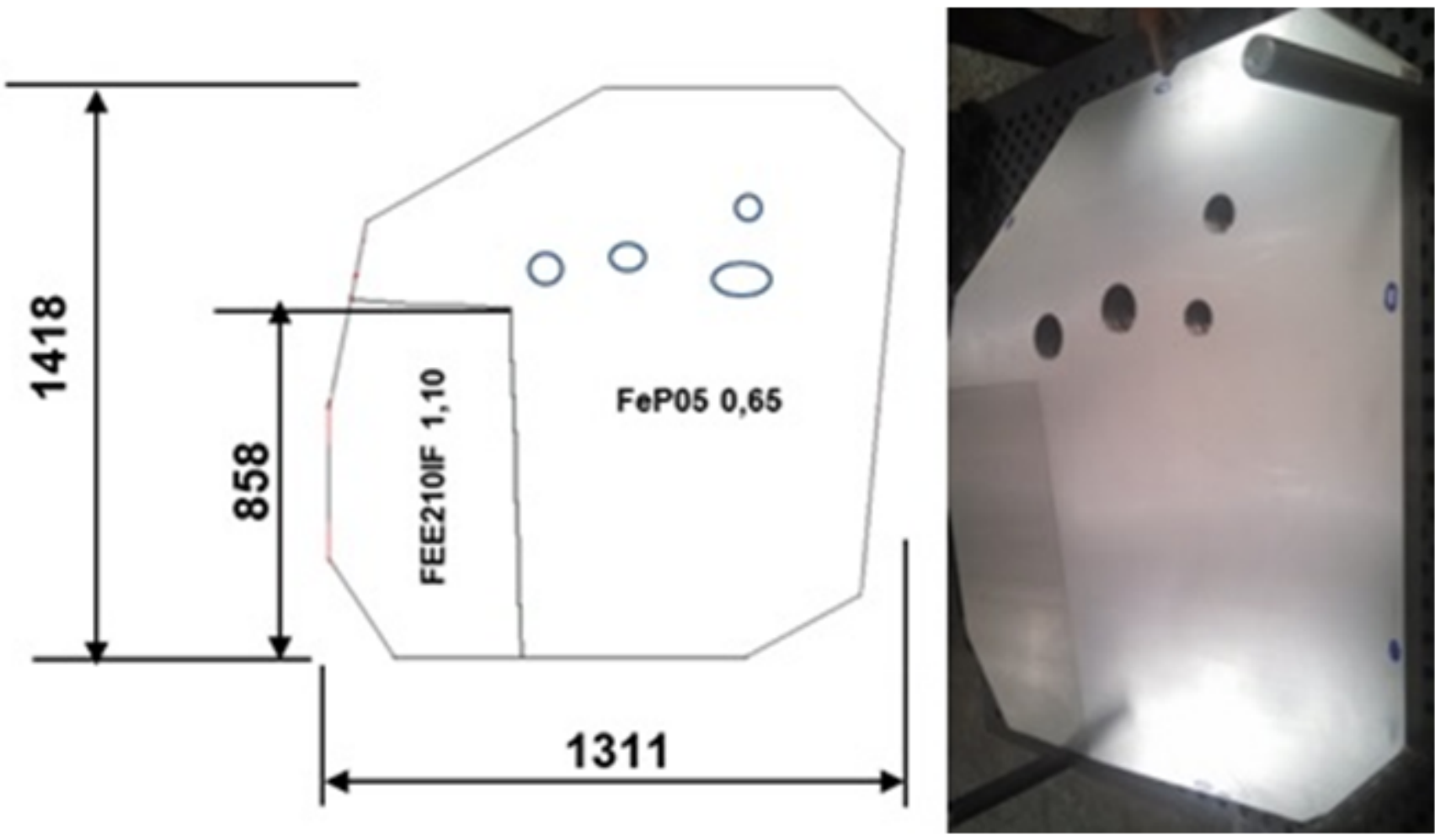
Figure 2

Schematic representation of the blank used to extract the specimens

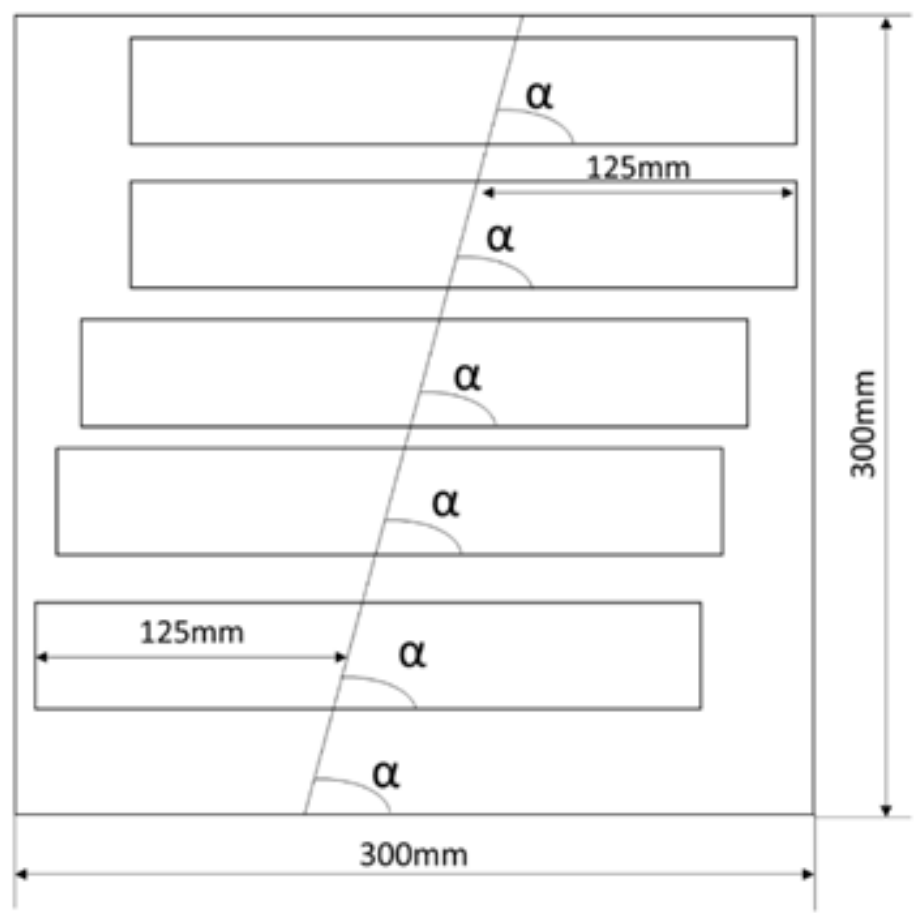

Figure 3

Schematic representation of the extract of tensile specimens 

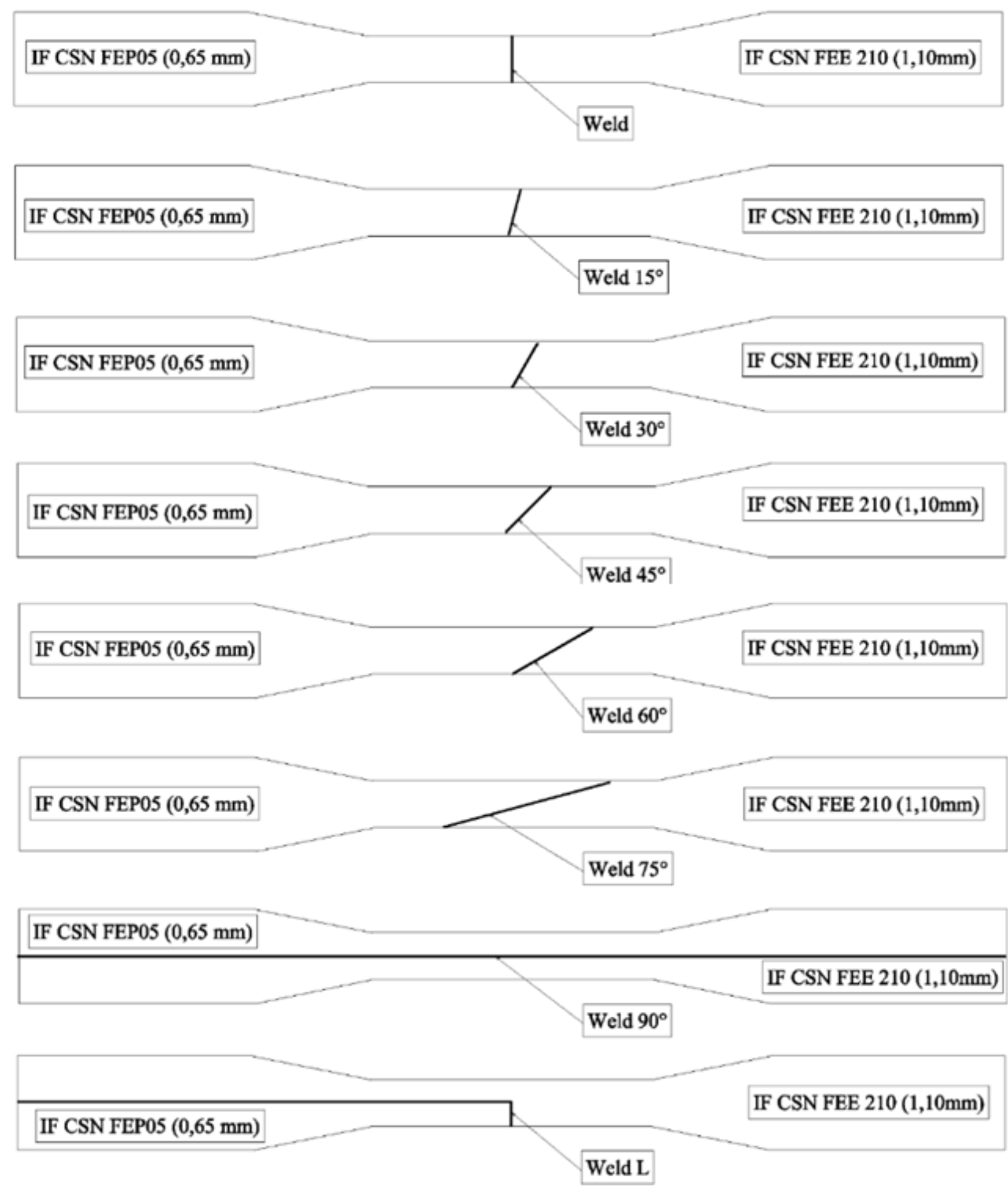

\section{Figure 4}

Specimens used in the uniaxial traction test. 


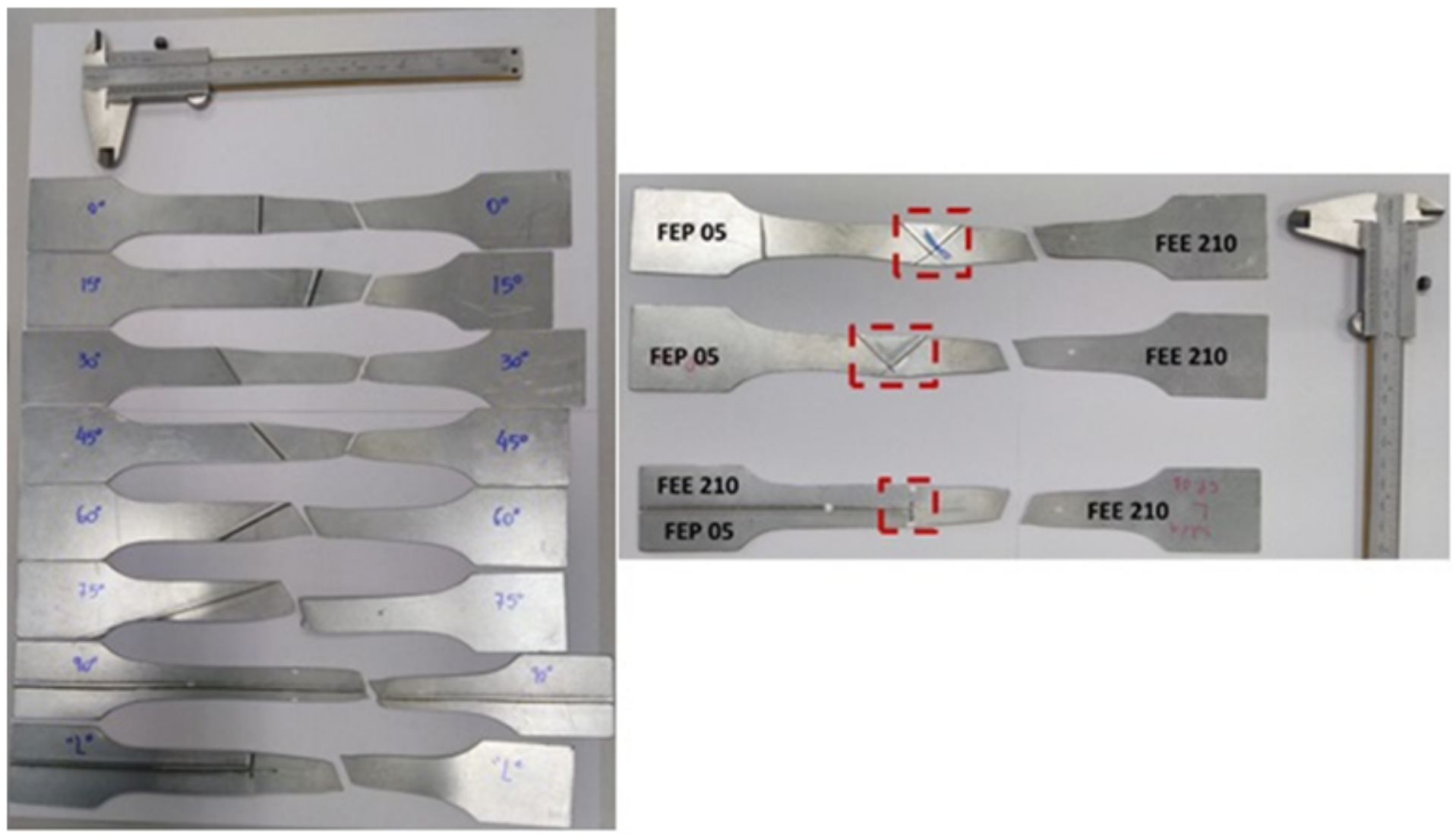

Figure 5

Qualitative result of the tensile test.

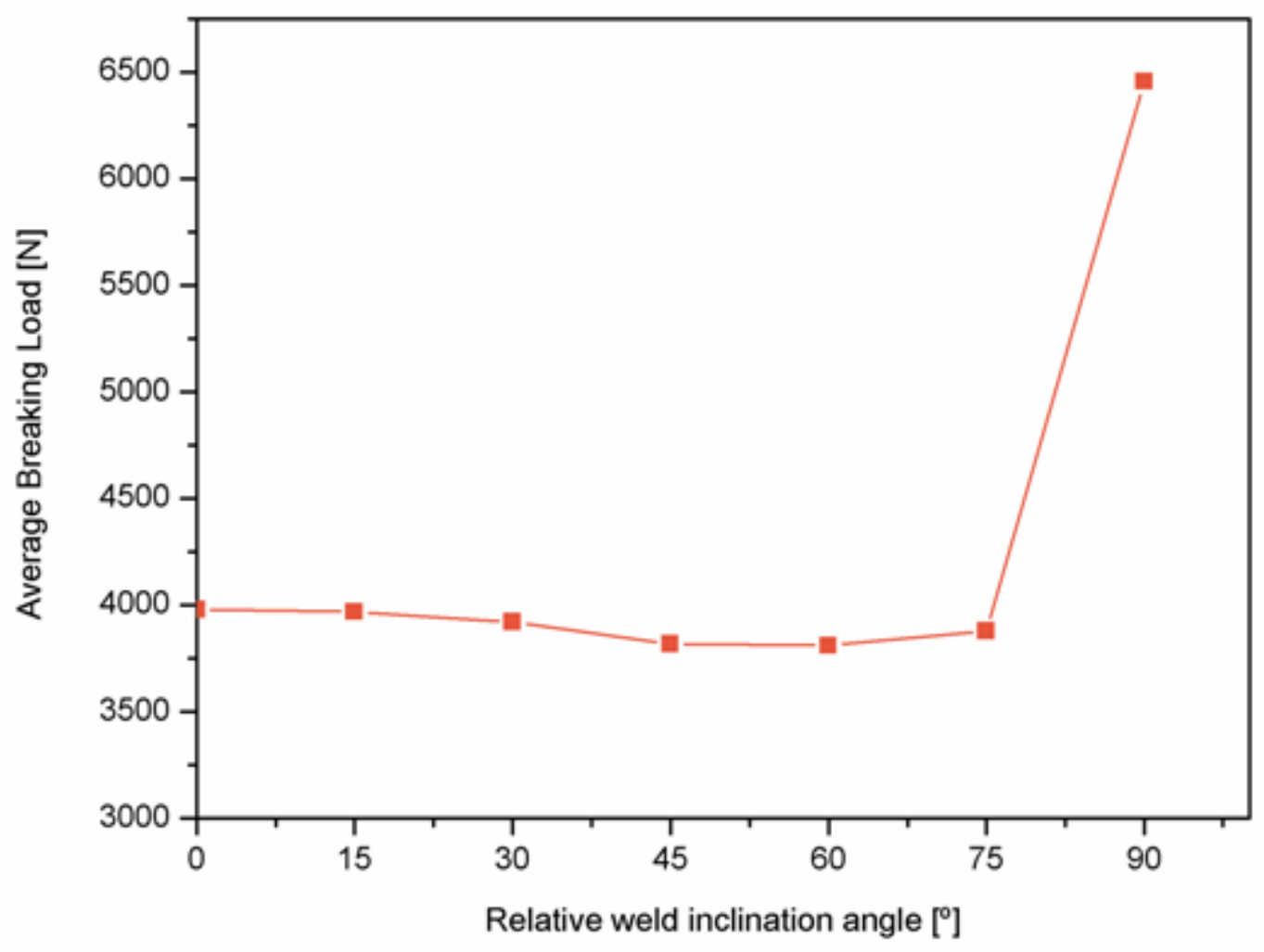

Figure 6 
Relationship between the breaking load and the relative angle of the welding line

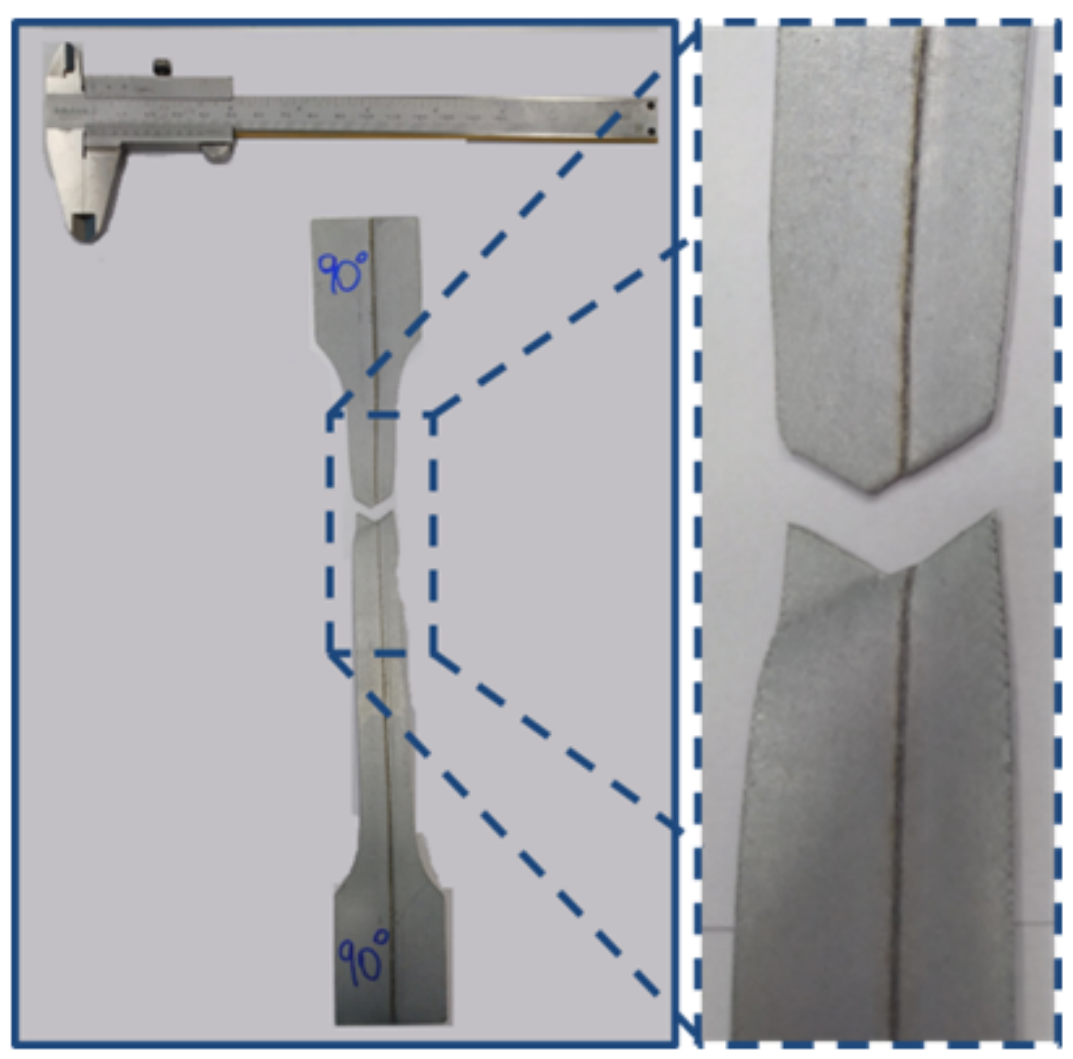

Figure 7

Tensile specimen with welding line oriented at $90^{\circ}$, covering its entire length, showing fracture profile 


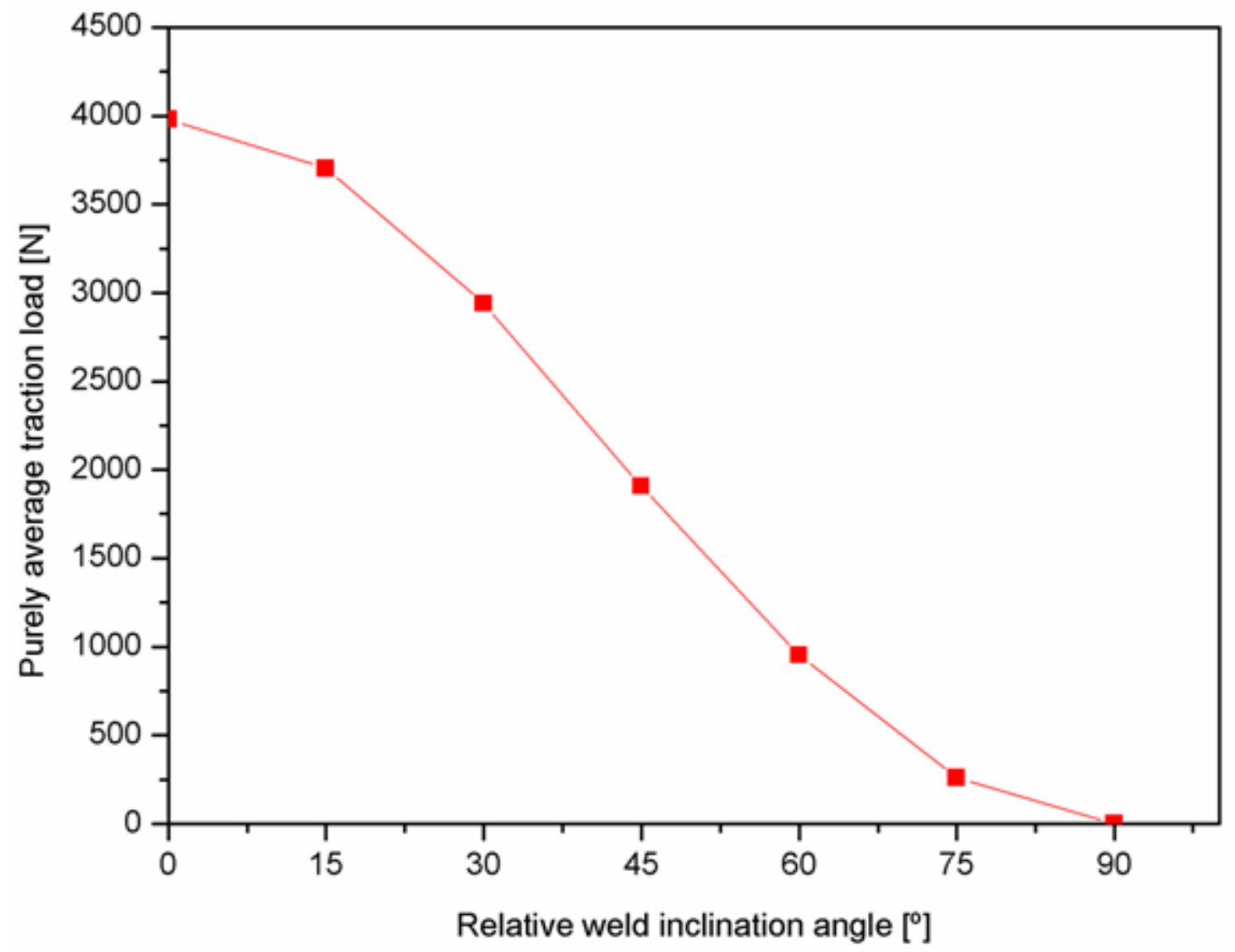

Figure 8

Relationship between the purely tensile load and the relative inclination angle of the weld line.

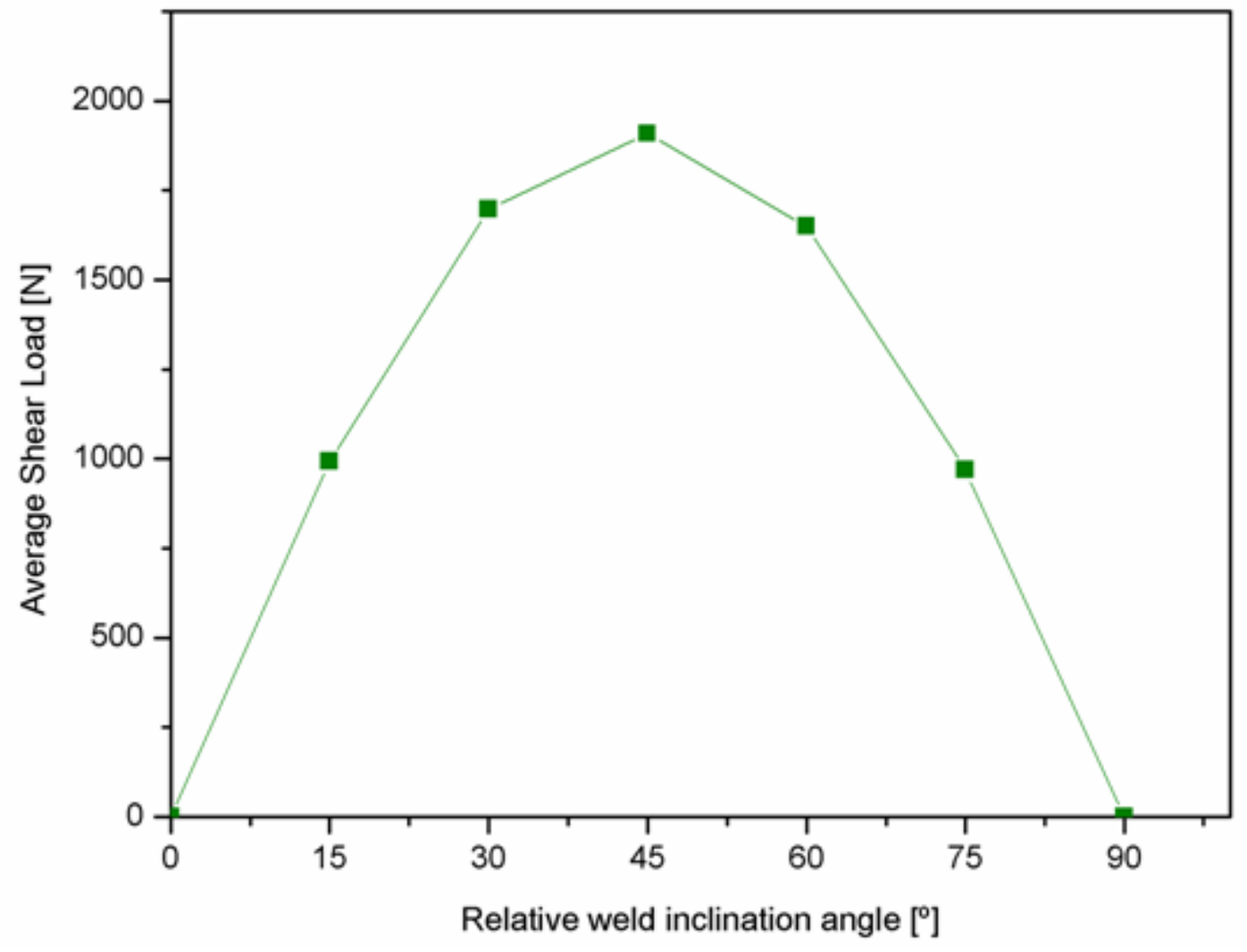

Page $18 / 22$ 
Figure 9

Relationship between the shear load and the relative inclination angle of the weld line

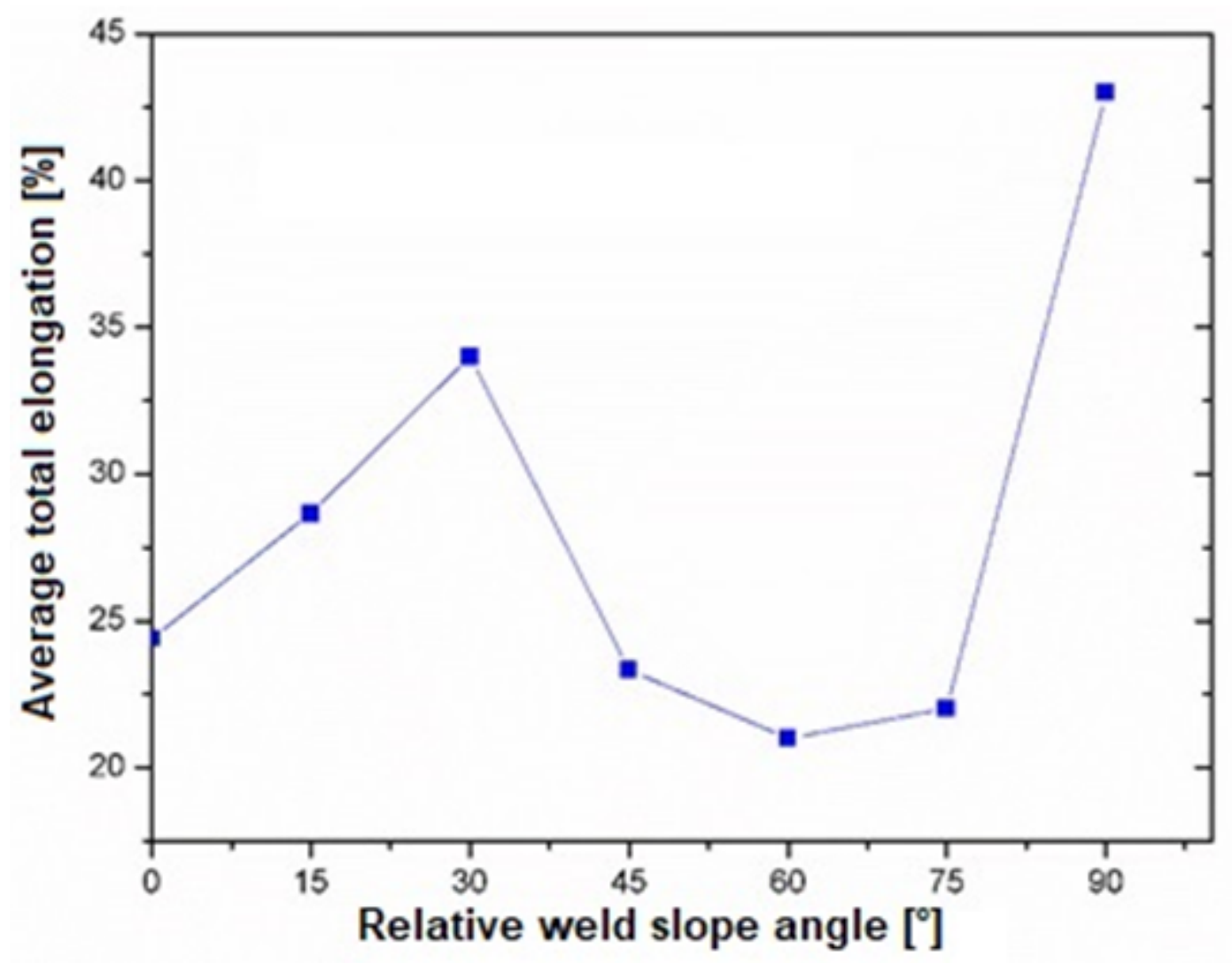

Figure 10

between the total elongation and the relative angle of the weld line 


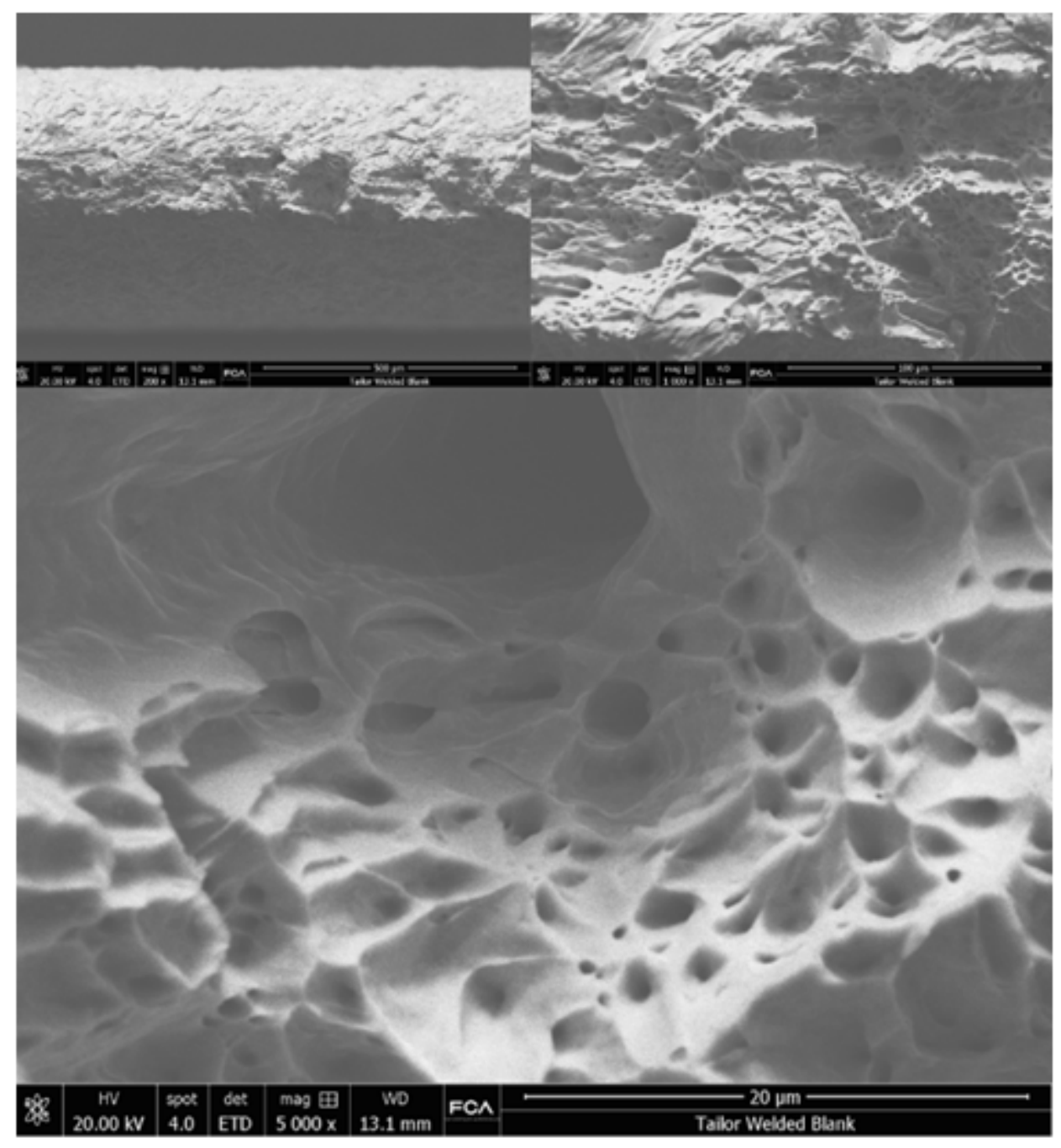

Figure 11

Electron beam scanning electron microscopy images for welding. 


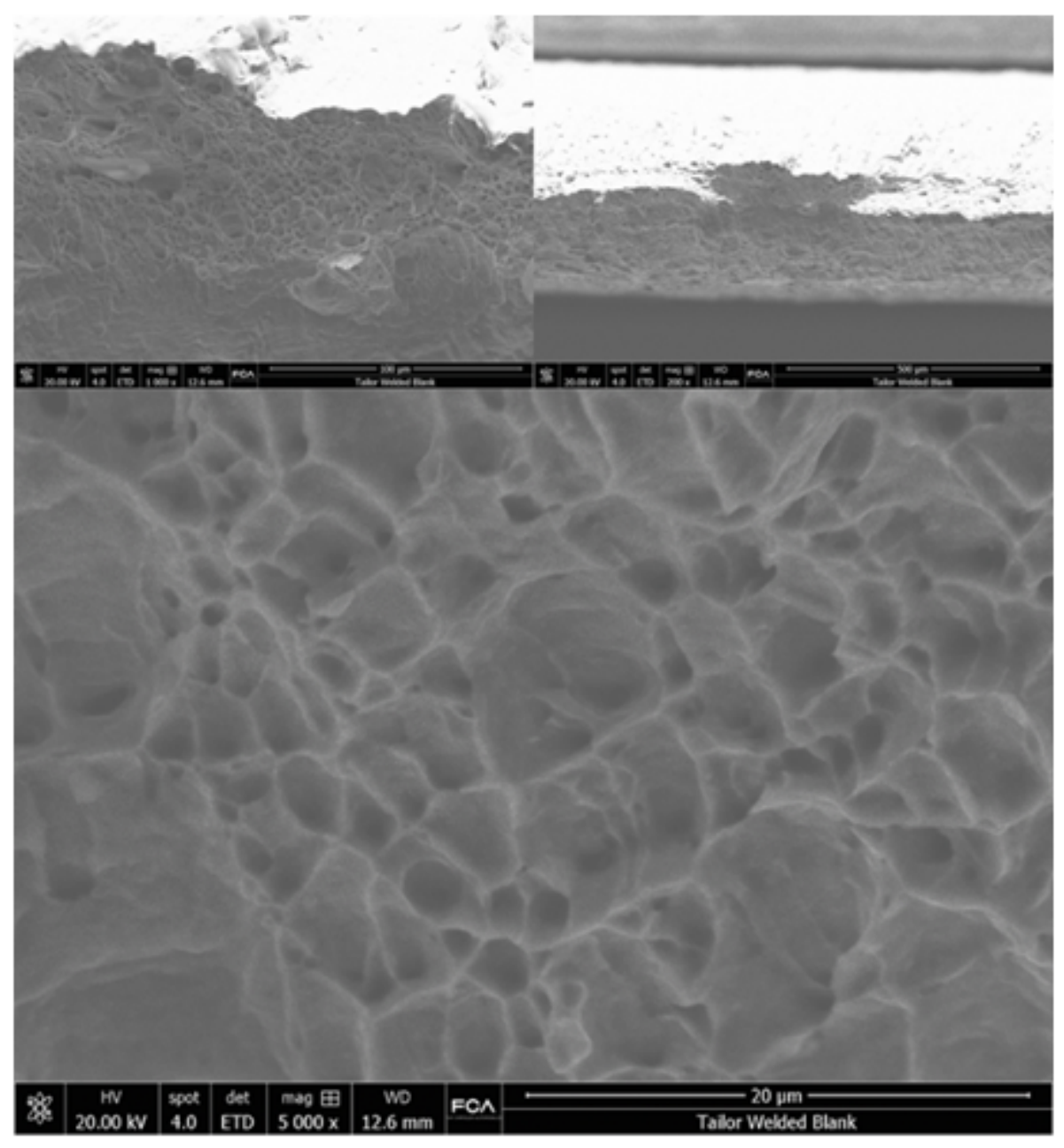

\section{Figure 12}

Images obtained by electron beam scanning electron microscopy for a sample with a relative inclination angle of the welding line of $30^{\circ}$. 


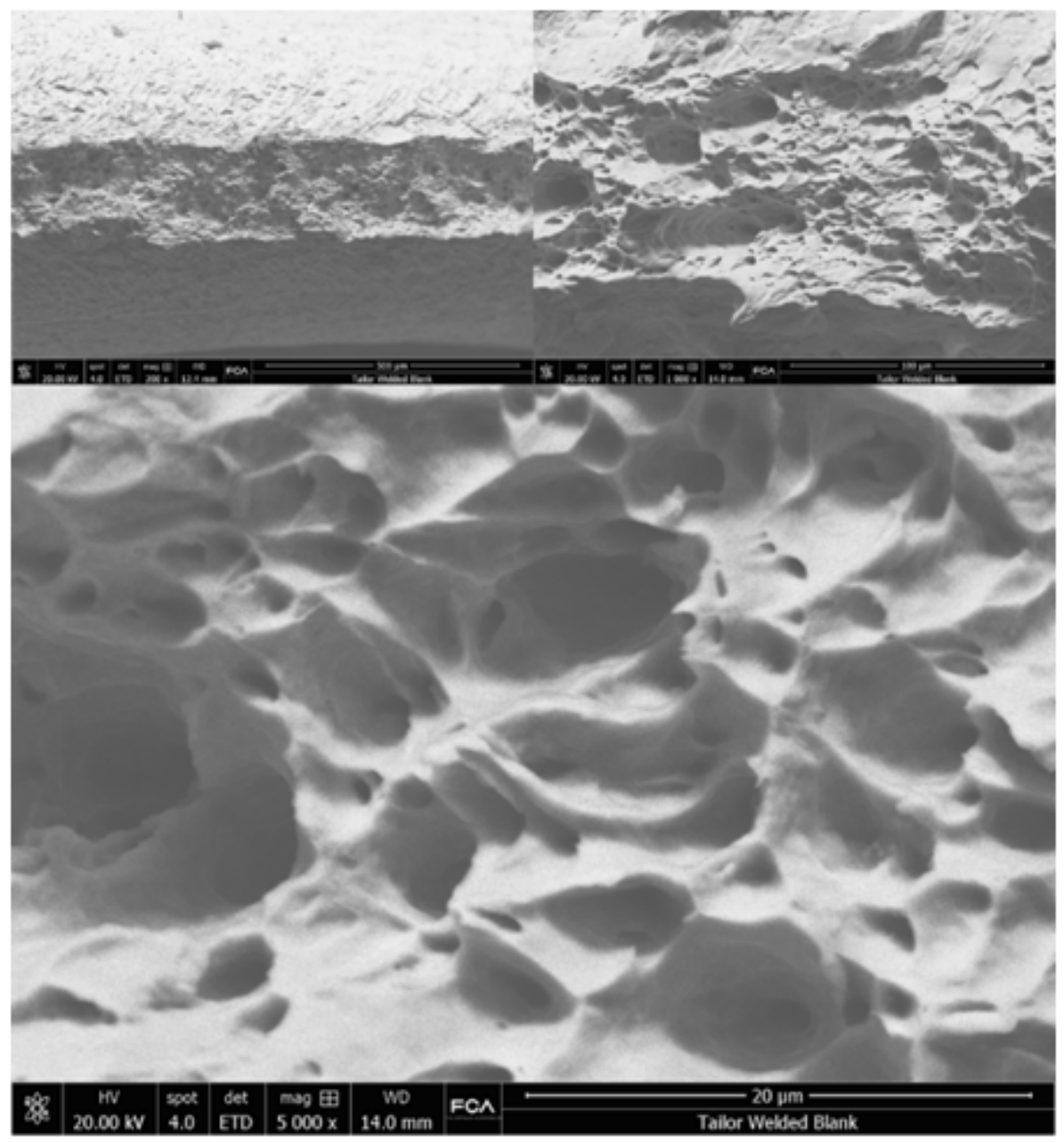

Figure 13

Images obtained by electron beam scanning electron microscopy for a sample with a relative inclination angle of the welding line of $90^{\circ}$ 